\title{
Globe
}

Revue internationale d'études québécoises

\section{Henri Lamoureux : Les Dérives de la démocratie. Questions à la société civile québécoise, Montréal, VLB éditeur, 1999, 159 p.}

\section{Luc Turgeon}

Volume 3, numéro 1, 2000

URI : https://id.erudit.org/iderudit/1000574ar

DOI : https://doi.org/10.7202/1000574ar

Aller au sommaire du numéro

Éditeur(s)

Globe, Revue internationale d'études québécoises

ISSN

1481-5869 (imprimé)

1923-8231 (numérique)

Découvrir la revue

Citer ce compte rendu

Turgeon, L. (2000). Compte rendu de [Henri Lamoureux : Les Dérives de la démocratie. Questions à la société civile québécoise, Montréal, VLB éditeur, 1999, 159 p.] Globe, 3(1), 169-171. https://doi.org/10.7202/1000574ar d'utilisation que vous pouvez consulter en ligne.

https://apropos.erudit.org/fr/usagers/politique-dutilisation/ 
pratique, et non pas théorique, des idéaux de la modernité. Cette synthèse est aussi pratique au sens où toute philosophie politique devrait l'être, pourrions-nous ajouter, c'est-à-dire au sens où elle contribue à faire apercevoir des solutions de rechange, à la fois faisables et moralement acceptables, pour des situations qui font présentement obstacle à l'émancipation des personnes et des sociétés. Tel est l'engagement philosophique qui se manifeste tout au long de cet ouvrage sans jamais porter ombrage à sa rigueur et à la perspicacité des analyses qu'il contient.

Jocelyne Couture

Université du Québec à Montréal

\section{Henri Lamoureux}

Les Dérives de la démocratie.

Questions à la société civile québécoise

Montréal, VLB éditeur, 1999, 159p.

Cet ouvrage s'inscrit dans un débat animé sur la transformation de la pratique sociale qui affecte le mouvement communautaire depuis quelques années. L'essayiste et romancier Henri Lamoureux, dans un style polémique qui n'est pas dépourvu de dérives verbales, tente de mettre au jour certaines tendances à l'œuvre au sein de la société civile qui détoumeraient cette dernière de son objectif d'émancipation de la population. Notons ici que le terme «société civile» est utilisé dans l'ouvrage dans son sens le plus idéaliste, entre autres comme uobstacle aux effets pervers d'une économie de marché» (p.12).

L'auteur identifie trois tendances au sein de la société civile qui menaceraient son idéal de démocratie et d'humanisme. La première est constituée du corporatisme des pratiques sociales (ou encore le néo-corporatisme selon les passages) qui «atteste l'importance croissante d'une vision utilitaire et économiste de l'action communautaire qui, faute d'avoir le courage d'adopter une 


\section{REVUE INTERNATIONALE D'ETUDES QUÉBECCOISES}

perspective transformatrice, s'accommode d'une perspective gestionnaire» (p.25). L'auteur s'en prend dans le chapitre consacré à cette question à l'approche consensuelle de l'Etat québécois dans la gestion des problèmes sociaux, approche corporatiste qui servirait des objectifs de contrôle social. Il est pour le moins paradoxal dans cette perspective que l'auteur dénonce la défense des intérêts particuliers dans la société civile au nom du bien commun. En effet, ce même discours du bien commun est en fait utilisé par l'État dans sa démarche consensuelle que Lamoureux dénonce. Cela tient à notre avis à la définition erronée de la société civile comme un ensemble relativement unifié que présente Henri Lamoureux, alors qu'il s'agit plutôt d'une sphère au sein de laquelle des conceptions du monde différentes s'opposent.

La deuxième tendance qu'identifie l'auteur est le passage d'une activité de militant, tournée vers la transformation de la société, à celle de gestionnaire des problèmes sociaux. Cette problématique s'inscrit dans le débat qui a cours depuis quelques années sur l'économie sociale. L'auteur n'amène guère de nouvelles perspectives à la question. Il est dommage qu'il n'ait pas utilisé son expérience dans des entreprises d'économie sociale pour discuter plus en détail des limites ou des potentialités de cette approche. La troisième tendance qu'il sent se développer est celle de l'élitisation de la représentation sociale. Cette dernière s'inscrit dans un contexte plus général qui marque les sociétés démocratiques : l'appropriation de la représentation par ces «intoxiqués du pouvoin» que sont les politiciens professionnels, les organisateurs de partis, les technocrates et les employés permanents de la société civile que l'auteur dénonce avec une virulence que ne renierait pas une certaine droite populiste. On peut se demander si cette élitisation de la représentation est une réalité nouvelle ou si elle n'est pas plutôt inscrite dans la logique même de la démocratie représentative, comme l'avait démontré au début du siècle Roberto Michel.

Finalement, l'auteur conclut l'ouvrage avec un chapitre somme toute banal sur la question nationale et le social, chapitre dont on comprend d'ailleurs mal l'insertion dans la discussion. Il fait l'économie d'une réflexion sérieuse sur les relations conflictuelles 


\section{RECENSIONS}

entre le mouvement nationaliste et les mouvements sociaux, au profit d'une charge à fond de train sur ceux qui an'aiment le Québec qu'à genoux». Plus intéressante est sans doute la discussion de la reconnaissance par la société civile canadienne-anglaise de l'identité et de la spécificité québécoise. L'auteur invite d'ailleurs la société politique à s'inspirer des pratiques qui ont cours entre les deux sociétés civiles. Cependant, il occulte par le fait même que certaines des composantes de la société civile canadienne-anglaise, entre autres le mouvement des femmes à l'occasion du lac Meech, ont été à l'avant-garde de la lutte contre la reconnaissance de la spécificité québécoise.

L'ouvrage de Henri Lamoureux ne fait donc pas dans la nuance et la subtilité. S'il pose des questions parfois pertinentes à la société civile québécoise, il n'en demeure pas moins que les constats sont souvent simplistes et peu originaux (le corporatisme qu'il décrit ressemble par exemple beaucoup plus à la définition du pluralisme à l'américaine), les pistes intéressantes sont laissées en suspens et les concepts utilisés rarement définis. Fort problématiques sont également les dérives verbales de l'auteur. Le contrôle des ressources premières par les multinationales est ainsi rapidement qualifié de néonazisme, le salaire d'un joueur de base-ball de forme moderne de fascisme et les politiques de promotion de l'identité canadienne de règle milosévicienne. Si on peut avec raison s'opposer à de telles pratiques, il n'en demeure pas moins que l'utilisation des termes nazisme et fascisme à toutes les sauces mène, à mon avis, à la banalisation de ces phénomènes, à la perte de conscience de leur unicité, et contribue à discréditer un questionnement pourtant nécessaire au sein du mouvement communautaire. 